\title{
Differences in hydrogeochemistry between shallow and deep aquifers in the Baiyangdian basin, China
}

\author{
Huaming Guo ${ }^{1,2, *}$, Zhaoli $\mathrm{Shen}^{2}$, Yi $\mathrm{Chen}^{1}$, Kai $\mathrm{Zhao}^{3}$, Haitao $\mathrm{Li}^{3}$, Wei Xiu ${ }^{1,2}$, and Lingbao \\ Weng $^{2}$ \\ ${ }^{1}$ State Key Laboratory of Biogeology and Environmental Geology, China University of Geosciences, \\ Beijing 100083, P.R. China \\ ${ }^{2}$ School of Water Resources and Environment, China University of Geosciences (Beijing), Beijing \\ 100083, P.R. China \\ ${ }^{3}$ China Institute of Geological Environment Monitoring, Beijing 100081, P. R. China
}

\begin{abstract}
Groundwater is the dominant long-term water resource for agricultural irrigation and industrial production in the Baiyangdian basin, North China Plain. Groundwater and pore-water were investigated to evaluate chemical evolution and geochemical processes in shallow and deep aquifers. Results show that both shallow groundwater and shallow pore-water had higher TDS, $\mathrm{Ca}^{2+}, \mathrm{Mg}^{2+}, \mathrm{SO}_{4}{ }^{2-}$, and $\mathrm{HCO}_{3}{ }^{-}$concentrations than deep groundwater and deep pore-water. Generally, concentrations of groundwater major ions were higher than those of pore-water in shallow aquifers, while they were slightly lower in groundwater than in pore-water from deep aquifers. Water isotopes showed the meteoric origin of groundwater and pore-water, although evaporation signature was traced in shallow groundwater. Shallow groundwater also experienced carbonate dissolution and silicate weathering. Silicate weathering and evaporite dissolution were the major hydrogeochemical processes in deep aquifers. This study indicated that deep groundwater has better water quality, but is vulnerable to contamination from shallow groundwater with high TDS and $\mathrm{NO}_{3}{ }^{-}$concentrations.
\end{abstract}

\section{Introduction}

Groundwater is generally the dominant long-term water resource for agricultural irrigation and industrial production in arid-semiarid areas [1-3], where groundwater quantity and quality are very important for ecological maintenance and social sustainability [4]. The North China Plain (NCP) is the largest alluvial plain in eastern Asia with serious water shortage, which poses great restrictions on economic development $[1,5]$. The Baiyangdian lake, the largest shallow (mean depth $<2 \mathrm{~m}$ ) freshwater wetland in NCP, plays an important role in drinking water supply, sustainable agriculture, climate regulation, and flood control [6]. In recent decades, intensified human activities have deteriorated the

\footnotetext{
*Corresponding author: hmguo@cugb.edu.cn
} 
hydrological conditions of the lake [7]. Therefore, this study is to investigate major chemical distributions of groundwater and pore-water and evaluate geochemical processes occurring in different aquifers, which would improve our understanding of chemical evolution of groundwater and help in sustainably managing water resources.

\section{Methods and Materials}

\subsection{Study area}

The Baiyangdian Basin, which belongs to the lacustrine deposits of NCP, is located to the southwest of Beijing and the east of Hebei province (Fig. 1). It has the largest freshwater shallow lake wetland (the Baiyangdian wetland) in NCP.

The topography slightly inclines from northwest to southeast, with the land slopes between $0.10 \%$ and $0.25 \%$ [8]. The Quaternary sediment thickness ranges between 500 and $600 \mathrm{~m}$, which is dominated by alluvial deposits interbedded with lacustrine deposits [9]. Due to the long-term exploitation, groundwater in the Holocene aquifer and the upper Pleistocene aquifer has mixed, which is assigned as shallow groundwater $(0-150 \mathrm{~m})$. For the same reason, deep groundwater mainly occurs in the remaining two aquifers (from 150 to $600 \mathrm{~m}$ ) [10]. Regional groundwater flow is from northwest to southeast. The hydraulic gradients range from $1 / 750$ to $1 / 2600$ [11]. The study area has been divided into Zone 1 and Zone 2, which represents upstream area and downstream area according to the groundwater flow, respectively (Fig. 1).

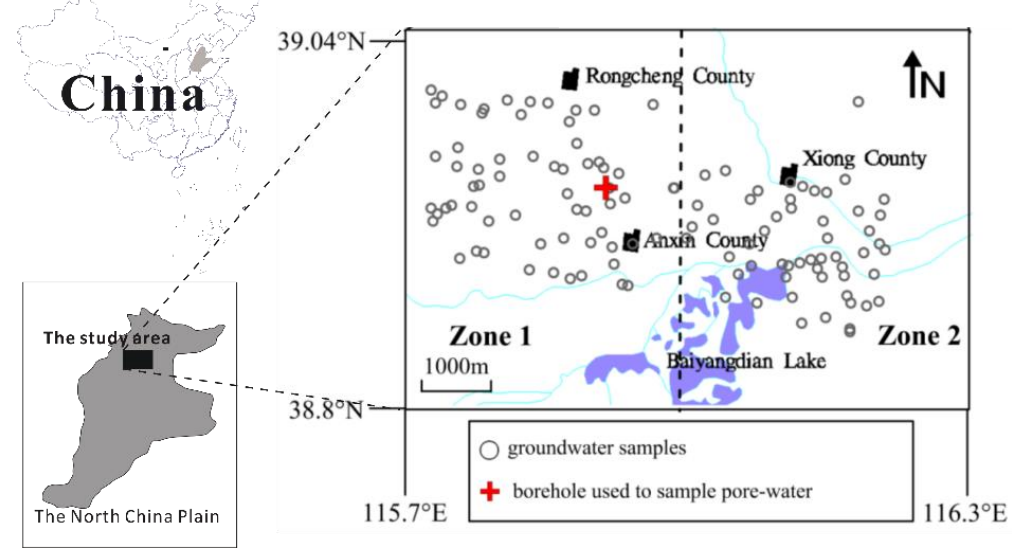

Fig. 1. Study area and sampling locations of groundwater and pore-water

\subsection{Groundwater and sediment sampling}

One hundred and seventeen groundwater samples were collected from electric-powered public water supply wells in the study area, including seventy-two shallow groundwater samples and forty-five deep groundwater samples (Fig. 1).

One representative borehole (ZK1), located in the Zone 1, was drilled to take sediment samples from different aquifers up to $600 \mathrm{~m}$ below land surface (Fig. 1). All sediments were transported to the laboratory at $4{ }^{\circ} \mathrm{C}$, and were stored at $-20{ }^{\circ} \mathrm{C}$ in the laboratory until analysis. Fifty-seven pore-water samples were extracted from sandy sediments of ZK1 using the high-speed centrifugation method, as previously done in many studies [12]. After centrifuge, suspension was filtered by $0.22 \mu \mathrm{m}$ filter membrane. 


\subsection{Sample analysis}

Concentrations of major cations and trace elements were detected by ICP-AES (iCAP6000, Thermo) and ICP-MS (7500C, Agilent), respectively. Major anions, including $\mathrm{NO}_{3}{ }^{-}, \mathrm{Cl}^{-}$, $\mathrm{SO}_{4}{ }^{2-}$, and $\mathrm{F}^{-}$, were determined using ion chromatography (ICS2000, Dionex). Ion charge imbalances were mostly better than $5 \%$.

Oxygen and hydrogen stable isotopes were analyzed by using L2120-i analyzer (Picarro, USA). These isotopic ratios of $\mathrm{D} / \mathrm{H}$ and ${ }^{18} \mathrm{O} /{ }^{16} \mathrm{O}$ are expressed as $\delta$ notation $[\delta=$ $1000\left(\mathrm{R}_{\text {Sample }} / \mathrm{R}_{\text {Standard }}-1\right)$ ] with respect to the VSMOW (Vienna Standard Mean Ocean Water) international standard. Analytical precisions of $\delta^{18} \mathrm{O}$ and $\delta \mathrm{D}$ were better than $\pm 0.2 \%$ o and $\pm 1 \%$, respectively.

\section{Results \& discussion}

\subsection{Major components}

Groundwater was neutral to weakly alkaline, with $\mathrm{pH}$ between 6.7 and 9.5 (average 7.7) and between 7.2 and 8.6 (average 8.2) in shallow and deep aquifers, respectively. $\mathrm{Na}^{+}$was the dominant cation, and $\mathrm{HCO}_{3}^{-}$was the major anion in both shallow and deep groundwaters. Shallow groundwater had higher salinity than deep groundwater. Groundwater showed big variations in total dissolved solid (TDS) in different aquifers, with the ranges between 264 and $6480 \mathrm{mg} / \mathrm{L}$ (average $1000 \mathrm{mg} / \mathrm{L}$ ) and between 264 and 1340 $\mathrm{mg} / \mathrm{L}$ (average $444 \mathrm{mg} / \mathrm{L}$ ) in shallow and deep groundwaters, respectively. Higher $\mathrm{SO}_{4}{ }^{2-}$ concentrations than $\mathrm{Cl}^{-}$was observed in shallow groundwater, while $\mathrm{SO}_{4}{ }^{2-}$ concentrations were lower than those of $\mathrm{Cl}^{-}$in deep groundwater (Fig. 2). Nevertheless, from Zone 1 to Zone 2, we can see a increasing trend in $\mathrm{Na}^{+}$concentration and a decreasing trend in $\mathrm{Ca}^{2+}$ concentrations.

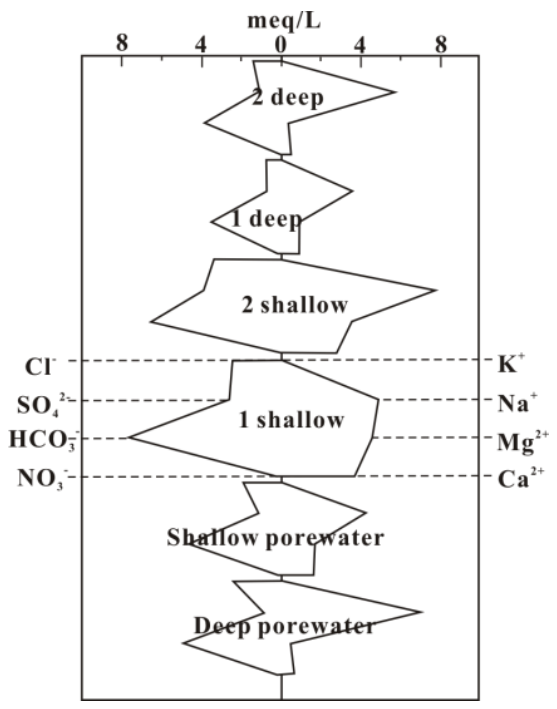

Fig. 2. Stiff plots of groundwater and pore-water in the study area (1 shallow: shallow groundwater in Zone 1; 2 shallow: shallow groundwater in Zone 2; 1 deep: deep groundwater in Zone 1; 2 deep: deep groundwater in Zone 2).

The pore-water had $\mathrm{pH}$ values from 7.5 to 8.36 and from 7.49 to 8.53 in shallow and deep pore-waters, respectively. The pore-water TDS had a range of 267 to $868 \mathrm{mg} / \mathrm{L}$ and 243 to $662 \mathrm{mg} / \mathrm{L}$ in shallow and deep aquifers, respectively. $\mathrm{HCO}_{3}{ }^{-}$was the major anion in 
both shallow and deep pore-waters, with concentrations up to 587 and $416 \mathrm{mg} / \mathrm{L}$, respectively. Meanwhile, $\mathrm{Na}^{+}$was the dominant cation with ranges of 38.2 to $397 \mathrm{mg} / \mathrm{L}$ and 72.1 to $263 \mathrm{mg} / \mathrm{L}$ in shallow and deep aquifers, respectively. Shallow pore-waters had more $\mathrm{Ca}^{2+}$ and $\mathrm{Mg}^{2+}$ but less $\mathrm{Na}^{+}$, compared with deep pore-waters. Deep pore-water samples showed similar major chemistry to the deep groundwater, while shallow pore-water had the distinct major chemistry with shallow groundwater (eg. shallow groundwaters had higher $\mathrm{SO}_{4}{ }^{2-}$ concentrations).

Groundwater and pore-water had similar concentrations of major components. Concentrations of $\mathrm{NO}_{3}{ }^{-}, \mathrm{SO}_{4}{ }^{2-}, \mathrm{Mg}^{2+}$ and $\mathrm{Ca}^{2+}$ in pore-water were identical to the groundwater, although concentrations of $\mathrm{K}^{+}$of pore-water were higher than groundwater both in shallow and deep aquifers, which may be the result of the release of adsorbed $\mathrm{K}^{+}$on clay minerals during the high speed centrifugation. Furthermore, concentrations of $\mathrm{HCO}_{3}{ }^{-}$, $\mathrm{Cl}^{-}$and $\mathrm{Na}^{+}$showed a decrease-increase pattern along the depth in pore-water, which were not discovered in groundwater.

\subsection{Hydrochemical processes in different aquifers}

Bivariate mixing diagrams have been used to understand the sources of major ions of the groundwater and pore-water in different aquifers [13]. The plots of Na-normalized $\mathrm{Ca}^{2+}$ versus Na-normalized $\mathrm{Mg}^{2+}$ and Na-normalized $\mathrm{HCO}_{3}{ }^{-}$were developed to examine the relative contribution of the three major weathering mechanisms (silicate, carbonate and evaporite) to solute concentrations in groundwater [14].

According to these plots (not shown), deep groundwater samples were within or close to the global-average evaporite dissolution domain. In contrast, shallow groundwater samples were plotted between the global-average carbonate dissolution and silicate weathering. Meanwhile, pore-water had a similar trend to the groundwater in Zone 1, indicating the similar hydrochemical processes in pore-water and groundwater.

\subsubsection{Hydrochemical processes in shallow aquifers}

Shallow groundwaters were enriched in heavier $\mathrm{H}$ and $\mathrm{O}$ isotopes, which indicated that shallow groundwaters were subject to evaporation. Carbonate dissolution and silicate weathering contributed to the major components of groundwater and pore-water in shallow aquifer. The shallow groundwater in Zone 1 mostly fell along the 1:2 trend line on the bivariate plot of $\mathrm{HCO}_{3}{ }^{-}$versus $\mathrm{Ca}^{2+}$ and $\mathrm{Mg}^{2+}$, which confirmed calcite weathering/dissolution. Some of the groundwater samples of Zone 1 fell along the 1:2 trend line on the bivariate plot of $\mathrm{HCO}_{3}{ }^{-}$versus $\mathrm{Na}^{+}$and $\mathrm{K}^{+}$, which showed that $\mathrm{Na}^{+}$and $\mathrm{K}^{+}$were primarily derived from weathering of micas and of plagioclase.

The ratio of $\mathrm{Na}^{+}$and $\mathrm{K}^{+}$to total cations tends to be the lowest for shallow groundwater in Zone 1 (median 0.57 for shallow groundwater in Zone 1, 0.77 for shallow groundwater in Zone 2, 0.88 for deep groundwater in Zone 1 and 0.91 for deep groundwater in Zone 2). The predominance of $\mathrm{Ca}^{2+}$ and $\mathrm{Mg}^{2+}$ for the shallow groundwater in Zone 1 showed that if silicate weathering was the primary mechanism of introduction of the bivalent cations, the sediment provenance would have to be dominated by alkaline earth silicates [15].

\subsubsection{Hydrochemical processes in deep aquifers}

In addition to silicate weathering, evaporite dissolution played an important role in the deep aquifers, as revealed by the bivariate plot (not shown) of $\mathrm{Cl} / \mathrm{Br}$ versus $\mathrm{Cl}^{-}$. The deep groundwater samples clustered nearly along the trend line of evaporite dissolution, suggesting that groundwater in deep aquifer were more primarily affected by the evaporite 
dissolution than that in shallow aquifer. Meanwhile, pore-water samples were consistent with groundwater in Zone 1, which means pore-water had similar hydrochemical processes with groundwater.

\section{Conclusions}

This paper studied the similarities and differences of pore-water and groundwater in Baiyangdian lake basin. In the study area, groundwater was neutral to weakly alkaline, with $\mathrm{Na}^{+}$and $\mathrm{HCO}_{3}{ }^{-}$being the dominant components. Shallow groundwater had higher TDS than deep groundwater, and there was an increasing trend and a decreasing trend of concentrations of $\mathrm{Na}^{+}$and $\mathrm{Ca}^{2+}$ along the groundwater flow, respectively. Concentrations of $\mathrm{HCO}_{3}^{-}, \mathrm{Cl}^{-}$and $\mathrm{Na}^{+}$showed decrease-increase patterns along the depth in pore-water, which were not discovered in groundwater. Different hydrochemical processes occurred in shallow and deep groundwater. Shallow groundwater were influenced by evaporation, carbonate dissolution and silicate weathering, while evaporite dissolution and silicate weathering played an important role in deep aquifer. Cation exchange occurred as well in all aquifers.

The study was financially supported by National Natural Science Foundation of China (Nos. 41222020 and 41825017) and the Geological survey project of China (No. 121201014000150013).

\section{References}

1. S.Q. Wang, X.F. Song, Q.X. Wang, G.Q. Xiao, C.M. Liu, J.R. Liu, J. Geograph. Sci. 19, 175-188 (2009)

2. I. Cartwright, T.R. Weaver, Hydrogeol. J. 13, 752-770 (2005)

3. J.L. Vanderzalm, P.J. Dillon, K.E. Barry, K. Miotlinski, J.K. Kirby, C. Le Gal La Salle, Appl. Geochem. 26, 1946-1955 (2011)

4. Y.B. Sun, S.G. Wu, D.D. Dong, T. Lüdmann, Y.H. Gong, Marine Geol. 311-314, 3240 (2012)

5. L.N. Xing, H.M. Guo, Y.H. Zhan, J Asian Earth Sci. 70-71, 250-264 (2013)

6. W. Guo, H.Y. Zhang, S.L. Huo, Ecol. Eng. 67, 150-155 (2014)

7. X. Li, B.S. Cui, Q.C. Yang, Y. Lan, Ecohydrology 9, 52-67 (2016)

8. W. Chen, Groundwater in Hebei, Seismological Press (1999) (in Chinese)

9. H. Chen, G.L. Wang, Z. Wei, Earth Environ. 33, 620-623 (2005) (in Chinese)

10. H.Y. Liu, H.M. Guo, L.N. Xing, Y.H. Zhan, F.L. Li, J.L. Shao, H. Niu, X. Liang, C.Q. Li, J. Asian Earth Sci. 117, 33-51 (2016)

11. Z.H. Zhang, Z.L. Shen, Y.Q. Xue, H.F. Ren, D.H. Shi, Z.Y. Yin, Z.X. Zhong, X.H. Sun, Groundwater Environmental Evolution in North China Plain (Geology Press, Beijing, 2000) (in Chinese)

12. G.T. Ankley, M.K. Schubauer-Berigan, J. Dierkes, Environ. Toxicol. Chem. 10, 1359 (1991)

13. A. Mukherjee, B.R. Scanlon, A.E. Fryar, D. Saha, A. Ghosh, S. Chowdhuri, R. Mishra, Geochim. Cosmochim. Acta 90, 283-302 (2012)

14. J. Gaillardet, B. Dupré, P. Louvat, C.J. Allègre, Chem. Geol. 159, 3-30 (1999)

15. M.M. Sarin, S. Krishnaswami, K. Dilli, B.L.K. Somayajulu, W.S. Moore, Geochim. Cosmochim. Acta 53, 997-1009 (1989) 